\title{
Predictors of Durable Immune Responses Six Months After the Last Vaccination in Preventive HIV Vaccine Trials
}

Yunda Huang ${ }^{a, b, c^{*}}$, Lily Zhang ${ }^{a, b}$, Holly Janes ${ }^{a, b, d}$, Nicole Frahm ${ }^{a, c}$, Abby Isaacs $^{a, b}$, Jerome H. Kim ${ }^{e, f}$, David Montefiori ${ }^{\mathrm{g}}$, M.

Julie McElrath ${ }^{\mathrm{a}, \mathrm{c}, \mathrm{h}, \mathrm{i}}$, Georgia D. Tomaras ${ }^{\mathrm{g}}$, Peter B. Gilbert ${ }^{\mathrm{a}, \mathrm{b}, \mathrm{d}}$ 
BACKGROUND The evaluation of durable immune responses is important in HIV vaccine research and development. The efficiency of such evaluation could be increased by incorporating predictors of the responses in the statistical analysis. In this paper, we investigated whether and how baseline demographic variables and immune responses measured two weeks after vaccination predicted durable immune responses measured six months later.

METHODS We included data from seven preventive HIV vaccine regimens evaluated in three clinical trials: a Phase 1 study of four DNA, NYVAC and/or AIDSVAX vaccine regimens (HVTN096), a Phase 2 study of two DNA and/or MVA vaccine regimens (HVTN205), and a Phase 3 study of a single ALVAC/AIDSVAX regimen (RV144). Regularized random forests and linear regression models were used to identify and evaluate predictors of the positivity and magnitude of durable immune responses.

RESULTS We analyzed 201 vaccine recipients with data from 10 to 127 immune response biomarkers, and 3 to 5 demographic variables. The best prediction of participants' durable response positivity based on two-week responses rendered up to close-to-perfect accuracy; the best prediction of participants' durable response magnitude rendered correlation coefficients between the observed and predicted responses ranging up to 0.91 . Though prediction performances differed among biomarkers, durable immune responses were best predicted by the two-week response level of the same biomarker. Adding demographic information and two-week response levels of different biomarkers provided little or no improvement in the predictions.

CONCLUSIONS For some biomarkers and for the vaccines we studied, two-week post-vaccination responses can well predict durable responses six months later. Therefore, if immune response durability is only assessed in a sub-sample of vaccine recipients, statistical analyses of durable responses will have increased efficiency by incorporating two-week response data. Further research is needed to generalize the findings to other vaccine regimens and biomarkers.

Clinicaltrials.gov identifiers:

NCT01799954, NCT00820846, NCT00223080. 
Key words: Binding antibody multiplex array; Immunogenicity; Intracellular cytokine staining; Regularised random forest; Statistical power.

2 Durable vaccine-induced immune responses are critical to minimize waning efficacy of vaccines against diverse 3 pathogens, including HIV-1 (e.g., [1-3]). An important objective of early-phase HIV vaccine clinical trials is to evaluate and

\section{Introduction} pathogens, in screen vaccine candidates based on immune responses measured at time points near the vaccinations (e.g., 2-4 weeks afterwards) and at later time points, including at an "early" durability (e.g., 6-12 months afterwards) time point [3]. Although vaccination-proximal responses are generally assessed in every trial participant, durability responses are sometimes only assessed in a subset of participants because of trial cost/length considerations and loss to follow-up.

Incomplete data at the durability time point potentially limits statistical power for immunogenicity profiling of candidate 9 vaccines. One viable solution is to incorporate immune response durability predictors into the analysis. For example, based on statistical methods described in $[4,5]$, a $25-50 \%$ efficiency gain (i.e., sample size savings) can be achieved in the comparison of durability immune responses between two groups if the predictor has a correlation of 0.6-0.8 with the durability response (Supplementary eFigure 1). To investigate whether this could be applied to the analysis of HIV vaccine-induced immune responses, we characterized predictors of cellular and humoral immune response durability using data from randomized HIV-1 vaccine clinical trials, focusing on biomarkers that have been validated and/or previously used as immunogenicity endpoints. The specific objectives of this analysis were to evaluate whether and how well a participant's 1) positivity and 2) magnitude of vaccine-induced cellular and humoral immune responses at an early durability time point can be predicted by that participant's immune responses of the same biomarker at the two-week post-vaccination time point. We also evaluated whether adding baseline demographic information and two-week response data from other biomarkers improved prediction.

ADCC, antibody-dependent cell-mediated cytotoxicity; AUC, area under the receiver operating characteristics curve; BAMA, binding antibody multiplex assay; $\mathrm{Cl}$, confidence interval; CV, cross-validation; ELISA, enzyme-linked immunosorbent assay; ELISpot, enzyme-linked immunospot; ICS, intracellular cytokine staining; Ig, immunoglobulin; MVA, modified vaccinia virus Ankara; OOB, out-of-bag; RRF, regularized random forest 


\subsection{Study Cohorts and Immune Response Biomarkers}

We analyzed data from seven vaccine regimens evaluated in three preventive HIV vaccine trials: a phase 1 study of four DNA, NYVAC and/or AIDSVAX vaccine regimens conducted in Switzerland (HVTN 096), a phase 2 study of two DNA and/or modified vaccinia virus Ankara (MVA) vaccine regimens in the USA and Peru (HVTN 205) [6], and a phase 3 study of a single ALVAC/AIDSVAX regimen in Thailand (RV144) [7] (Table 1). Final vaccinations were given at Month 6 for all regimens. We restricted analysis to vaccine recipients who received all planned immunizations and were HIV-uninfected at the time of immune response assessments. For HVTN 205 and RV144, data were available from a randomly selected subset of vaccine recipients in the original studies $[6,7]$.

Immune response biomarkers were measured at the two-week and 6-month (durability) post-vaccination time points, which corresponded to study visits at week 26 and week52 and are referred to as the wk26 and wk52 responses. At both time points responses were measured with by cellular assays [B cell enzyme-linked immunospot (ELISpot) [8], CD4+ and CD8+ intracellular cytokine staining (ICS) [9], and Bio-Plex cytokine Luminex [10]] and antibody assays [antibodydependent cell-mediated cytotoxicity (ADCC) [11]; immunoglobulin (Ig)G avidity [12]; IgA, IgG, IgG3 and IgG4-binding antibody multiplex assay (BAMA) [13-16]; and enzyme-linked immunosorbent assay (ELISA) [17]] (Table 1). Immune response positivity and magnitude were defined as previously described [6, 13]. For the available RV144 data [13], different subsets of vaccine recipients were randomly selected for the cellular and antibody assays, except for the avidity and BAMA assays. For HVTN096 and HVTN205, all assays were performed on the same set of vaccine recipients.

\subsection{Statistical methods}

\section{Modeling methods}

To accommodate the large number of predictors, regularized random forests (RRFs) $[18,19]$ of 5000 classification or regression trees (stratified resampling by vaccine regimen for HVTN 096 and HVTN 205) were used to model wk52 response positivity or magnitude, respectively, for each biomarker within each trial. In addition, univariate logistic regression or linear regression models were performed to predict wk52 response positivity or magnitude, respectively, using wk26 response magnitude from the same immune response biomarker as the predictor (adjusted for treatment assignment in HVTN205). Immune response biomarkers were log-transformed when appropriate to satisfy modeling assumptions. All analyses were performed using R version 3.2.1 [20]. 
48 To ensure sufficient variability and sample size, immune response biomarkers were excluded if their wk52 response rate

49 was $<15 \%$ in all vaccine regimens of a given study. Several baseline predictors were considered: HIV risk category (low, 50 medium and high) [7], gender (male vs. female), age category in years (>=26, 21-25, vs. $<=20$ in RV144; >= vs. < trial-

51 specific median otherwise), body mass index (>= vs. < trial-specific median), race (white vs. other), and country (USA vs.

52 other) (Table 1$)$

53 To evaluate the incremental value of including additional predictors other than the wk26 immune response of the same 54 biomarker, two types of RRF models - "same wk26 response" univariable, and "same + other wk26 responses"

55 multivariable - were used. The former included as predictors only the wk26 response magnitude of the same biomarker, 56 whereas the latter included as predictors, wk26 response magnitudes of all measured biomarkers, with and without the 57 baseline predictors. The latter is used unless otherwise stated.

\section{$58 \quad$ Prediction approaches}

59 Predictions accounted for the knowledge that immune responses to vaccination generally do not increase from 2 weeks 60 post to 6 months post last immunization. Specifically, for a given biomarker, wk26-negative vaccine recipients were 61 predicted to be wk52-negative and the wk52 response magnitude was predicted to be half of the smallest response magnitude of the responders for the same biomarker. For wk26-positive vaccine recipients, the predicted wk52 value was based on the corresponding modeling of the wk26 positive responders. Results based on an alternative approach based on the modeling of all vaccine recipients, regardless of their wk26 positivity, are described in Supplementary eTable 1 \& eFigure 2.

\section{Prediction accuracy assessment}

67 The RRF predictions were based on "out-of-bag" (OOB) observations that were not used in the construction of a given 68 tree and then aggregated across all trees $[18,19]$. A random 2-fold cross-validation (CV) procedure $[21,22]$ was used to 69 assess regression model-based predictions. Specifically, models were built using a randomly chosen $50 \%$ training subset of the data, and validated on the remaining $50 \%$ of the test data set; results were then aggregated over 1000 validation

71 subsets. Area under the receiver operating characteristics curve (AUC) was used to evaluate prediction accuracy of wk52 
response positivity. The reported $95 \%$ confidence interval $(\mathrm{Cl})$ was computed based on a bootstrap procedure

73 (Supplementary Materials). An AUC value of 1.0 indicates perfect classification accuracy, whereas an AUC value of 0.5

74 indicates no better than random classification accuracy. Spearman's correlation coefficients between the predicted vs.

75 observed response magnitudes were calculated to evaluate the ability of wk26 response magnitude to predict wk52

76 magnitude.

\section{Results}

78 We analyzed data from 201 participants who received 7 different vaccine regimens in 3 studies (Table 1). Each study 79 considered 10 to 127 cellular and humoral immune response biomarkers and 3 to 5 baseline variables. The observed wk26 and wk52 response rates ranged widely $(0-100 \%)$ across the different biomarkers (Table 2 \& eTable 2$)$. Figure 1 and eFigure 3 show the time-trends of IgG binding antibody immune responses (Panel A) and CD4+ ICS immune responses (Panel B) at wk26 and wk52 across the regimens. The time-trends of neutralizing antibody responses, IgG3 and total IgG binding antibody responses, and avidity responses are shown in Supplementary eFigure 4. On average, responses waned to lower-magnitude positive responses, whereas in other participants, responses waned entirely (i.e. became negative). This heterogeneity in wk52 positivity was also seen across all vaccine regimens. In addition, the response magnitudes at $w k 26$ and $w k 52$ demonstrated a reasonably broad range for most biomarkers. We note that the antibody responses generated by these vaccine regimens were generally high in magnitude whereas the $\mathrm{T}$ cell response magnitudes appear more heterogeneous. In addition, medium-to-high positive correlations (inter-quartile range: 0.38 0.66) were observed between wk26 and wk52 responses of the same biomarker (Figure 2 Panel A). Wk26 vs. wk52 responses of different biomarkers were also mostly positively correlated but with lower correlation coefficients (Figure

For Objective 1, both RRF- and logistic regression-based predictions of wk52 response positivity were reasonably accurate, with AUC estimates consistently higher than 0.5 for most biomarkers (Table 2 \& eTable 2). For several biomarkers in each study, the lower bound of the $95 \% \mathrm{Cl}$ for the AUC was above 0.8 , reflecting excellent prediction accuracy. On the other hand, poor prediction was observed for avidity and IgG4 responses in RV144. However, this was 
not surprising since antibody avidity can persist despite declining concentrations of specific antibody, and IgG4

responses have naturally delayed kinetics post-antigen stimulation. Indeed, we found increased IgG4 responses from

wk26 to wk52 for a few vaccine recipients. Poor prediction was also observed for $\lg G$ binding antibody responses to one V1V2 antigen (gp70 B.CaseA V1V2) and neutralization antibody response to one isolate (MW965.26) in HVTN 096, possibly due to the low variability in wk26 response magnitudes and the low wk52 response rate (eFigure 4).

In general, the prediction of wk52 response positivity was not improved by adding baseline demographic variables or other wk26 immune responses as predictors. As shown in Table 2, the AUC values based on the univariable regression models were generally comparable to those based on RRF, suggesting that wk26 response of the same biomarker explained the majority of the variation in wk52 response positivity for most of the biomarkers. A formal comparison of the RRF prediction of wk52 response positivity between the "same wk26 responses" and "same + other wk26 responses" models is illustrated in Supplementary eTable 1 based on HVTN 205 data; little to no improvement in prediction was seen in the latter models.

Results for Objective 2 were similar to those for Objective 1. Specifically, the performance of RRF-based prediction ranged widely, with correlation coefficients between the observed and OOB-predicted wk52 response magnitudes varying from close to 0 to above 0.8 for different biomarkers (Table $3 \&$ eTable 3). Wk26 response magnitudes of biomarkers with sufficient variability at both time points could predict wk52 response magnitudes. Panel A in Figure 3 shows an example in RV144 in which the correlation between the observed and predicted wk52 IgA binding antibody response to a gp120 antigen (A244gp120gDpos293Tmon) was high with $\rho_{\text {pred-RRF }}=0.86$ when using either the "same wk26 response" model (left panel) or the "same + other wk26 responses" model (right panel). This result is consistent with the high correlation coefficient $\rho_{\mathrm{obs}}=0.92$ between wk26 and wk52 responses for this biomarker. Panel B in Figure 3 shows another example for the IgA binding antibody response to a different gp120 antigen (GNE8rgp120Qpool), in which the prediction was less accurate, with correlation coefficient $\rho_{\mathrm{obs}}=0.73$ between the observed wk 26 and wk52 responses. However, the prediction improved slightly when other wk26 biomarkers were included as predictors ( $\rho_{\text {pred-RRF }}$ $=0.72$ vs. 0.57$)$. Poor prediction was observed for biomarkers with a low correlation between the observed wk26 and wk52 responses. Panel C in Figure 3 shows an example in RV144 for the IgG binding antibody response to another gp120 antigen (gp70 BCaseA2V1V2mut3) with $\rho_{\text {obs }}=0.38$, in which the prediction using the same wk26 immune response was 
poor $\left(\rho_{\text {pred-RRF }}=0.10\right)$ but was improved $\left(\rho_{\text {pred-RRF }}=0.55\right)$ when other $w k 26$ immune responses were also included as

predictors. Of note, the patterns in Panel A, followed by Panel B, were most commonly observed in our analysis.

As for Objective 1, the prediction of wk52 response magnitude was not improved by adding other wk26 immune responses as predictors for the majority of biomarkers, with the exceptions described above. Univariable linear regression-based prediction resulted in a higher correlation coefficient $\left(\rho_{\text {pred-reg }}\right)$ between the predicted and observed wk52 response magnitudes when the observed correlation ( $\left.\rho_{\text {obs }}\right)$ was higher for a given biomarker (Table 3 , last column), confirming that wk26 response of the same biomarker explained the majority of the variation in wk52 response magnitude. A formal comparison of the RRF prediction of wk52 response magnitudes between the "same wk26 responses" and "same + other wk26 responses" models is illustrated in Supplementary eTable 4 and eFigure 5 using HVTN205 data; little to no improvement in prediction was seen in the latter models.

\section{Discussion}

The vaccine regimens generated cellular and humoral immune responses against different antigens at a broad range of response rates and response magnitudes. We observed that, regardless of the absolute levels of these responses or the time-trend between the two time points, the two-week and six-month post immune responses of the same or different biomarkers were generally positively correlated, with correlation coefficients up to $90 \%$. In addition, using different prediction methods, we consistently observed that both the positivity and magnitude of 6-month durable immune responses were best predicted by the two-week response level of the same biomarker. Prediction performance varied across biomarkers and across studies. For a few biomarkers, two-week immune responses could explain up to $80 \%$ of the variability in the response durability of the same biomarker. These findings are based on real data and provide compelling evidence that statistical efficiency for comparing durable immune responses between HIV vaccine regimens in trials that only measure durable responses in a subset can be increased by as much as $50 \%$ by incorporating the twoweek immune response data into the analysis. We observed moderate-to-excellent prediction for biomarkers with sufficient variability in both wk26 and wk52 response magnitudes, indicating that prediction performance is driven less by the absolute percentage of positive responses at either time point and more by having a reasonably wide dynamic response range at both time points. For example, we observed a larger variation in the predicted wk52 responses for 
wk52-negative responders (Figure 3), possibly due to the fact that some of these vaccine recipients were wk26-positive responders with large variation in their wk52 responses. Specifically, some wk26-positive responses waned to a lower response magnitude at wk52 while others waned to a negative wk52 response.

Moreover, prediction performance seems to depend on both the vaccine regimen and biomarker. Adding baseline demographic variables or two-week immune responses from other biomarkers generally did not improve the prediction beyond that based on the two-week immune response of the same biomarker. This finding indicates that the measured immune responses were generally not redundant, but instead each captured distinct immunological functions.

Several other factors could also explain the imperfect predictions of wk52 responses. First, assay technical measurement error diminishes the strength of association that can be detected. Second, variability between vaccine recipients in the time between the last immunization and specimen collection for measuring immune responses diminishes associations, although our previous analysis (data not shown) indicated that only a small fraction of the variability in immune responses is explained by sampling time. Third, the sample sizes were limited. Lastly, unmeasured factors (e.g., host genetics, innate immunity factors) were not considered in the analyses but may be associated with wk52 responses. proximal to HIV vaccinations in predicting durable immune responses 6 months later. Various mathematical models have been proposed to predict the long-term decay of antibody levels after vaccination against hepatitis A [23-28], hepatitis B [29], and HPV [30, 31]. However, our context, goals, data, and methods were different. First, no HIV vaccine with sufficient magnitude and durability of vaccine efficacy to warrant licensure has yet been identified and thus a highpriority task is to increase efficiency in the evaluation of multiple candidate vaccines. The goal of our analysis was to assess whether two-week and 6-month immune responses are correlated, because if so, this finding would support advocating the incorporation of two-week immune responses into the analysis of durable immune responses to increase the efficiency of such analyses. On the other hand, the cited analyses focused on the prediction of long-term antibody levels for licensed efficacious vaccines where the scheduling of a possible booster vaccine is more relevant. Second, previous research involved durable immune responses measured at more time points that were further in time after the immunization series. Because of these different goals, the durable immune responses in our analyses were restricted to 6 months, as opposed to years after vaccination as in the cited analyses. For HIV Env-specific antibody 
responses, 6 months post-last immunization may be after the initial rapid exponential decline phase of these responses

(e.g., [3, 32]). Third, we used different predictors and analysis tools. In addition to studying prediction accuracy of demographic variables and individual two-week immune response biomarkers for the same biomarker at 6 months, we also studied prediction accuracy of two-week immune response biomarkers that are different from the response biomarker being predicted. Furthermore, due to the high-dimensionality of our predictors, we employed modern statistical analysis tools as opposed to the traditional mathematical modeling techniques used previously.

Our analysis has some caveats. First, although we included extensive data from seven vaccine regimens in populations with different HIV risks, our findings will still need to be validated for other vaccine concepts/biomarkers. Second, we identified a few biomarkers in each study whose two-week response was highly predictive of its durable response. However, it was outside the scope of our analyses to identify the deterministic factors of the durable immune responses for a particular vaccine regimen. Third, we did not observe any specific patterns with respect to correlations between two-week and durable immune responses for a given vaccine concept (e.g., DNA prime) compared to another (e.g., vector prime), possibly due to limited sample sizes. Larger studies are required to discover such patterns. Lastly, vaccineinduced antibodies may not be essential for achieving long-term vaccine efficacy when persistent immunological memory is evident [33]. For example, the strength of immune memory and of a subsequent secondary immune response was shown to be predicted by the antibody response following primary vaccination against hepatitis B [34]. Hence, future investigations of the prediction and modeling of durable HIV vaccine-induced immune responses are of interest.

\section{AUTHOR CONTRIBUTIONS}

YH, PBG planned the analysis.

$\mathrm{YH}, \mathrm{LZ}$, and $\mathrm{Al}$ retrieved the data from existing databases.

$\mathrm{NF}, \mathrm{JM}, \mathrm{JK}, \mathrm{DM}$, and GT acquired data.

$\mathrm{YH}, \mathrm{LZ}$, and Al performed the statistical analyses.

YH, LZ, DM, GT, HJ, and PBG interpreted the study results.

YH, LZ, and PBG wrote the manuscript. 
201 No conflicts of interest.

\section{PREVIOUS PRESENTATION}

Part of this work was presented at the HIV Vaccine Trials Network Full Group Meeting in May, 2015 in Washington DC, USA.

Acknowledgements: The authors thank the HVTN096, HVTN 205, and RV144 study participants and study teams for their dedication and contributions to the original studies; Global Solutions for Infectious Disease, Hua-Xin Liao, Barton F. Haynes, Nicole L. Yates, S and Munir Alam for their contributions to the assay measurements; Alicia Sato for the processing of HVTN205 data; Shannon Grant for the processing of HVTN 096 data; Youyi Fong and Allan DeCamp for the processing of RV144 data; George Lewis for helpful comments on the analyses; and Lindsay Carpp for editorial assistance.

Funding: This work was supported by the National Institutes of Health [UM1 AI068635, UM1 AI068614, and UM1 Al068618]. The RV144 study was supported by a cooperative agreement [W81XWH-11-2-0174] between the Henry M. Jackson Foundation for the Advancement of Military Medicine, Inc. and the U.S. Department of Defense (DoD). The views expressed are those of the authors and should not be construed to represent the positions of the U.S. Army or the DoD. This work was partially supported by contract \# 792087 from the Henry Jackson Foundation for the Military HIV Research Program. 
[1] Amanna IJ, Carlson NE, Slifka MK. Duration of humoral immunity to common viral and vaccine antigens. N Engl J Med. 2007;357:1903-15.

[2] Yates NL, Liao HX, Fong Y, deCamp A, Vandergrift NA, Williams WT, et al. Vaccine-induced Env V1-V2 IgG3 correlates with lower HIV-1 infection risk and declines soon after vaccination. Sci Transl Med. 2014;6:228ra39.

[3] Lewis GK, DeVico AL, Gallo RC. Antibody persistence and T-cell balance: two key factors confronting HIV vaccine development. Proc Natl Acad Sci U S A. 2014;111:15614-21.

[4] Gilbert PB, Sato A, Sun X, Mehrotra DV. Efficient and robust method for comparing the immunogenicity of candidate vaccines in randomized clinical trials. Vaccine. 2009;27:396-401.

[5] Gilbert PB, Yu X, Rotnitzky A. Optimal auxiliary-covariate-based two-phase sampling design for semiparametric efficient estimation of a mean or mean difference, with application to clinical trials. Stat Med. 2014;33:901-17.

[6] Goepfert PA, Elizaga ML, Seaton K, Tomaras GD, Montefiori DC, Sato A, et al. Specificity and 6-month durability of immune responses induced by DNA and recombinant modified vaccinia Ankara vaccines expressing HIV-1 virus-like particles. J Infect Dis. 2014;210:99-110.

[7] Rerks-Ngarm S, Pitisuttithum P, Nitayaphan S, Kaewkungwal J, Chiu J, Paris R, et al. Vaccination with ALVAC and AIDSVAX to prevent HIV-1 infection in Thailand. N Engl J Med. 2009;361:2209-20.

[8] Walsh PN, Friedrich DP, Williams JA, Smith RJ, Stewart TL, Carter DK, et al. Optimization and qualification of a memory B-cell ELISpot for the detection of vaccine-induced memory responses in HIV vaccine trials. J Immunol Methods. 2013;394:84-93.

[9] Horton H, Thomas EP, Stucky JA, Frank I, Moodie Z, Huang Y, et al. Optimization and validation of an 8-color intracellular cytokine staining (ICS) assay to quantify antigen-specific T cells induced by vaccination. J Immunol Methods. 2007;323:39-54.

[10] Tomaras GD, Yates NL, Liu P, Qin L, Fouda GG, Chavez LL, et al. Initial B-cell responses to transmitted human immunodeficiency virus type 1: virion-binding immunoglobulin $\mathrm{M}$ (IgM) and IgG antibodies followed by plasma anti-gp41 antibodies with ineffective control of initial viremia. J Virol. 2008;82:12449-63. 
[11] Bonsignori M, Pollara J, Moody MA, Alpert MD, Chen X, Hwang KK, et al. Antibody-dependent cellular cytotoxicitymediating antibodies from an HIV-1 vaccine efficacy trial target multiple epitopes and preferentially use the VH1 gene family. J Virol. 2012;86:11521-32.

[12] Seaton KE, Lan A, Goepfert P, Alam SM, Parekh B, Robinson HL, et al. Increased Avidity Index to Immunodominant Epitope of HIV-1 gp41 Env with MVA prime/boost Vs. DNA Prime MVA/boost In Human HIV-1 Vaccine Trial (HVTN 065). . Poster Presentation, Keystone Symposia, HIV Vaccines2012.

[13] Haynes BF, Gilbert PB, McElrath MJ, Zolla-Pazner S, Tomaras GD, Alam SM, et al. Immune-correlates analysis of an HIV-1 vaccine efficacy trial. N Engl J Med. 2012;366:1275-86.

[14] Liao HX, Bonsignori M, Alam SM, McLellan JS, Tomaras GD, Moody MA, et al. Vaccine induction of antibodies against a structurally heterogeneous site of immune pressure within HIV-1 envelope protein variable regions 1 and 2 . Immunity. 2013;38:176-86.

[15] Liao HX, Lynch R, Zhou T, Gao F, Alam SM, Boyd SD, et al. Co-evolution of a broadly neutralizing HIV-1 antibody and founder virus. Nature. 2013;496:469-76.

[16] Yates NL, Stacey AR, Nolen TL, Vandergrift NA, Moody MA, Montefiori DC, et al. HIV-1 gp41 envelope IgA is frequently elicited after transmission but has an initial short response half-life. Mucosal Immunol. 2013;6:692-703.

[17] Karasavvas N, Billings E, Rao M, Williams C, Zolla-Pazner S, Bailer RT, et al. The Thai Phase III HIV Type 1 Vaccine trial (RV144) regimen induces antibodies that target conserved regions within the V2 loop of gp120. AIDS Res Hum Retroviruses. 2012;28:1444-57.

[18] Breiman L. Random Forests. Machine Learning. 2001;45:5-32.

[19] Deng H, Runger G. Gene selection with guided regularized random forest. Pattern Recogn. 2013;46:3483-9.

[20] R Core Team (2015). R: A language and environment for statistical computing. Foundation for Statistical Computing, Vienna, Austria. 2015.

[21] Lachenbruch PA, Mickey MR. Estimation of error rates in discriminant analysis. Technometrics. 1968;10:1-12. [22] Hastie T, Tibshirani R, Friedman J. The Elements of Statistical Learning. Springer; 2009.

[23] Van Herck K, Beutels P, Van Damme P, Beutels M, Van den Dries J, Briantais $P$, et al. Mathematical models for assessment of long-term persistence of antibodies after vaccination with two inactivated hepatitis A vaccines. J Med Virol. 2000;60:1-7. 
[24] Van Herck K, Van Damme P. Inactivated hepatitis A vaccine-induced antibodies: follow-up and estimates of longterm persistence. J Med Virol. 2001;63:1-7.

[25] Bovier PA, Bock J, Loutan L, Farinelli T, Glueck R, Herzog C. Long-term immunogenicity of an inactivated virosome hepatitis A vaccine. J Med Virol. 2002;68:489-93.

[26] Andraud M, Lejeune O, Musoro JZ, Ogunjimi B, Beutels P, Hens N. Living on three time scales: the dynamics of plasma cell and antibody populations illustrated for hepatitis a virus. PLoS Comput Biol. 2012;8:e1002418.

[27] Hens N, Habteab Ghebretinsae A, Hardt K, Van Damme P, Van Herck K. Model based estimates of long-term persistence of inactivated hepatitis A vaccine-induced antibodies in adults. Vaccine. 2014;32:1507-13.

[28] Theeten H, Van Herck K, Van Der Meeren O, Crasta P, Van Damme P, Hens N. Long-term antibody persistence after vaccination with a 2-dose Havrix (inactivated hepatitis A vaccine): 20 years of observed data, and long-term modelbased predictions. Vaccine. 2015;33:5723-7.

[29] Honorati MC, Palareti A, Dolzani P, Busachi CA, Rizzoli R, Facchini A. A mathematical model predicting anti-hepatitis B virus surface antigen ( $\mathrm{HBs}$ ) decay after vaccination against hepatitis B. Clinical \& Experimental Immunology. 1999;116:121-6.

[30] Fraser C, Tomassini JE, Xi L, Golm G, Watson M, Giuliano AR, et al. Modeling the long-term antibody response of a human papillomavirus (HPV) virus-like particle (VLP) type 16 prophylactic vaccine. Vaccine. 2007;25:4324-33.

[31] David M-P, Van Herck K, Hardt K, Tibaldi F, Dubin G, Descamps D, et al. Long-term persistence of anti-HPV-16 and 18 antibodies induced by vaccination with the AS04-adjuvanted cervical cancer vaccine: Modeling of sustained antibody responses. Gynecologic Oncology. 2009;115:S1-S6.

[32] Montefiori DC, Karnasuta C, Huang Y, Ahmed H, Gilbert P, de Souza MS, et al. Magnitude and breadth of the neutralizing antibody response in the RV144 and Vax003 HIV-1 vaccine efficacy trials. J Infect Dis. 2012;206:431-41.

[33] West DJ, Calandra GB. Vaccine induced immunologic memory for hepatitis B surface antigen: implications for policy on booster vaccination. Vaccine. 1996;14:1019-27.

[34] Banatvala J, Van Damme P, Oehen S. Lifelong protection against hepatitis B: the role of vaccine immunogenicity in immune memory. Vaccine. 2000;19:877-85. 
Table 1: Summary of Study Data.

\begin{tabular}{|c|c|c|c|c|c|c|c|}
\hline & HVTN096 ${ }^{1}$ & HVTN096 ${ }^{2}$ & HVTN096 ${ }^{3}$ & HVTN096 ${ }^{4}$ & HVTN205 ${ }^{5}$ & HVTN205 ${ }^{6}$ & RV144 \\
\hline $\begin{array}{l}\text { Vaccine } \\
\text { Regimen }\end{array}$ & $\begin{array}{l}\text { NYVAC (M 0) } \\
\text { NYVAC (M 1) } \\
\text { NYVAC/AIDSVAX } \\
\text { (M 3) } \\
\text { NYVAC/AIDSVAX } \\
\text { (M 6) }\end{array}$ & $\begin{array}{l}\text { NYVAC/AIDSVAX } \\
\text { (M 0) } \\
\text { NYVAC/AIDSVAX } \\
\text { (M 1) } \\
\text { NYVAC/AIDSVAX } \\
\text { (M 3) } \\
\text { NYVAC/AIDSVAX } \\
\text { (M 6) } \\
\end{array}$ & $\begin{array}{l}\text { DNA (M 0) } \\
\text { DNA (M 1) } \\
\text { NYVAC/AIDSVAX } \\
\text { (M 3) } \\
\text { NYVAC/AIDSVAX } \\
\text { (M 6) }\end{array}$ & $\begin{array}{l}\text { DNA/AIDSVAX } \\
\text { (M 0) } \\
\text { DNA/AIDSVAX } \\
\text { (M 1) } \\
\text { NYVAC/AIDSVAX } \\
\text { (M 3) } \\
\text { NYVAC/AIDSVAX } \\
\text { (M 6) } \\
\end{array}$ & $\begin{array}{l}\text { DNA (M O) } \\
\text { DNA (M 2) } \\
\text { MVA (M } \\
\text { 4) } \\
\text { MVA (M } \\
6 \text { ) }\end{array}$ & $\begin{array}{l}\text { MVA (M } \\
\text { 0) } \\
\text { MVA (M } \\
\text { 2) } \\
\text { MVA (M } \\
\text { 6) }\end{array}$ & $\begin{array}{l}\text { ALVAC (M 0) } \\
\text { ALVAC (M 1) } \\
\text { ALVAC/AIDSVAX } \\
\text { (M 3) } \\
\text { ALVAC/AIDSVAX } \\
\text { (M 6) }\end{array}$ \\
\hline $\begin{array}{l}\text { Total \# fully } \\
\text { immunized } \\
\text { vaccine } \\
\text { recipients with } \\
\text { immunogenicity } \\
\text { data }\end{array}$ & 20 & 20 & 20 & 20 & 46 & 35 & 40 \\
\hline $\begin{array}{l}\text { Baseline } \\
\text { variables }\end{array}$ & \multicolumn{4}{|c|}{ Gender, Age, BMI, Race } & \multicolumn{2}{|c|}{$\begin{array}{l}\text { Gender, Age, BMI, } \\
\text { Race, Country }\end{array}$} & $\begin{array}{l}\text { HIV Risk, } \\
\text { Gender, Age }\end{array}$ \\
\hline $\begin{array}{l}\text { Cellular assays } \\
\text { (\# readouts by } \\
\text { each assay) }\end{array}$ & \multicolumn{4}{|c|}{$\begin{array}{l}\text { CD4+ ICS (5) } \\
\text { CD8+ ICS (5) }\end{array}$} & \multicolumn{2}{|c|}{$\begin{array}{l}\text { CD4+ ICS (3) } \\
\text { CD8+ ICS (3) }\end{array}$} & $\begin{array}{l}\text { B cell ELISpot (4) } \\
\text { Cytokine } \\
\text { Luminex (12) } \\
\text { CD4+ ICS (2) } \\
\text { CD8+ ICS (2) }\end{array}$ \\
\hline $\begin{array}{l}\text { Antibody assays } \\
\text { (\# readouts by } \\
\text { each assay) }\end{array}$ & \multicolumn{4}{|c|}{$\begin{array}{l}\text { Neutralizing antibody (7) } \\
\text { BAMA IgA binding (10) } \\
\text { BAMA IgG binding (10) } \\
\text { BAMA IgG3 binding (10) }\end{array}$} & \multicolumn{2}{|c|}{ BAMA IgG binding (4) } & $\begin{array}{l}\text { ADCC (1) } \\
\text { Avidity IgG (8) } \\
\text { BAMA IgA } \\
\text { binding (21) } \\
\text { BAMA IgG } \\
\text { binding (8) } \\
\text { BAMA IgG3 } \\
\text { binding (9) } \\
\text { BAMA IgG4 } \\
\text { binding (21) } \\
\text { ELISA binding } \\
\text { (39) }\end{array}$ \\
\hline
\end{tabular}

BAMA, binding antibody multiplex assay; ELISA, enzyme-linked immunosorbent assay; ELISpot, enzyme-linked immunospot; ICS, intracellular cytokine staining; $M$, month.

Superscripts refer to specific vaccine regimens, as follows: ${ }^{1} \mathrm{~N} / \mathrm{N} / \mathrm{NA} / \mathrm{NA},{ }^{2} \mathrm{NA} / \mathrm{NA} / \mathrm{NA} / \mathrm{NA},{ }^{3} \mathrm{D} / \mathrm{D} / \mathrm{NA} / \mathrm{NA},{ }^{4} \mathrm{DA} / \mathrm{DA} / \mathrm{NA} / \mathrm{NA}$, ${ }^{5}$ DDMM, ${ }^{6}$ MMM. N, NYVAC (Viral Vector - Pox); NA, NYVAC/AIDSVAX (Viral Vector - Pox/Protein); D, DNA (DNA-based); DA, DNA/AIDSVAX (DNA/Protein); DDMM, DNA/DNA/modified vaccinia virus Ankara (MVA)/MVA; MMM, MVA/MVA/MVA. 
Table 2: Prediction of wk52 response positivity by RRF-based and univariate regression-based models. Regularized random forests (same+other) were used to model wk52 response positivity for each biomarker within each study. Univariate linear regression models were also used to predict wk52 response positivity for each biomarker using its wk26 magnitude as the predictor. Results are reported as area under the ROC curve (AUC) based on out-of-bag prediction (RRF) or cross-validation (univariate).

\begin{tabular}{|c|c|c|c|c|c|c|c|c|}
\hline \multirow[b]{2}{*}{ Study } & \multirow[b]{2}{*}{ Assay } & \multirow[b]{2}{*}{ Assay reagent* } & \multicolumn{2}{|c|}{ Observed } & \multicolumn{2}{|c|}{ RRF-based prediction } & \multicolumn{2}{|c|}{$\begin{array}{c}\text { Univariate regression- } \\
\text { based prediction }\end{array}$} \\
\hline & & & $\begin{array}{c}\text { Wk26 } \\
\text { response rate } \\
(\%)\end{array}$ & $\begin{array}{c}\text { Wk52 } \\
\text { response } \\
\text { rate (\%) }\end{array}$ & $\begin{array}{c}O O B \\
A \cup C(s d)\end{array}$ & $\begin{array}{l}95 \% \mathrm{Cl} \text { of } \\
\quad \mathrm{AUC}\end{array}$ & $\begin{array}{c}C V \\
A \cup C(s d)\end{array}$ & $95 \% \mathrm{Cl}$ of $\mathrm{AUC}$ \\
\hline \multirow{18}{*}{$\begin{array}{l}\text { HVTNO } \\
96^{1-4}\end{array}$} & $\begin{array}{l}\text { IgA binding } \\
\text { antibody }\end{array}$ & p24 & $11,7,69,47$ & $0,7,38,24$ & $\begin{array}{c}0.83 \\
(0.0688)\end{array}$ & $(0.69,0.96)$ & $\begin{array}{c}0.91 \\
(0.0836)\end{array}$ & $(0.75,1.00)$ \\
\hline & \multirow{10}{*}{$\begin{array}{l}\text { IgG binding } \\
\text { antibody }\end{array}$} & Con 6 gp120/B & $\begin{array}{c}100,100,100 \\
100\end{array}$ & $78,67,93,71$ & $\begin{array}{c}0.78 \\
(0.0606)\end{array}$ & $(0.66,0.90)$ & $\begin{array}{c}0.83 \\
(0.1070)\end{array}$ & $(0.62,1.00)$ \\
\hline & & Con S gp140 CFI & $\begin{array}{c}100,100,100 \\
100\end{array}$ & $67,40,93,76$ & $\begin{array}{c}0.74 \\
(0.0405)\end{array}$ & $(0.66,0.82)$ & $\begin{array}{c}0.85 \\
(0.0767)\end{array}$ & $(0.70,1.00)$ \\
\hline & & $\begin{array}{l}\text { A244 gp 120 } \\
\text { gDneg/293F/mon }\end{array}$ & $\begin{array}{c}100,100,100 \\
100\end{array}$ & $61,47,80,71$ & $\begin{array}{c}0.82 \\
(0.0269)\end{array}$ & $(0.77,0.87)$ & $\begin{array}{c}0.75 \\
(0.1154)\end{array}$ & $(0.53,0.98)$ \\
\hline & & AE.A244 V1V2 Tags/293F & $\begin{array}{c}100,100,100 \\
100\end{array}$ & $50,57,60,65$ & $\begin{array}{c}0.79 \\
(0.0238)\end{array}$ & $(0.75,0.84)$ & $\begin{array}{c}0.81 \\
(0.0828)\end{array}$ & $(0.65,0.97)$ \\
\hline & & gp41 & $78,87,100,88$ & $22,20,67,29$ & $\begin{array}{c}0.86 \\
(0.0239) \\
\end{array}$ & $(0.81,0.91)$ & $\begin{array}{c}0.88 \\
(0.0647) \\
\end{array}$ & $(0.75,1.00)$ \\
\hline & & $\begin{array}{l}\text { gp70 B.CaseA2 } \\
\text { V1/V2/169K }\end{array}$ & $\begin{array}{c}100,100,93,1 \\
00\end{array}$ & $11,20,20,24$ & $\begin{array}{c}0.82 \\
(0.0516)\end{array}$ & $(0.72,0.93)$ & $\begin{array}{c}0.85 \\
(0.0742)\end{array}$ & $(0.70,1.00)$ \\
\hline & & gp70 B.CaseA V1 V2 & $\begin{array}{c}100,100,100 \\
100\end{array}$ & $6,13,7,18$ & $\begin{array}{c}0.54 \\
(0.1225)\end{array}$ & $(0.30,0.78)$ & $\begin{array}{c}0.82 \\
(0.1138)\end{array}$ & $(0.60,1.00)$ \\
\hline & & MN gp120 gDneg/293T & $\begin{array}{c}100,100,100 \\
100\end{array}$ & $11,14,47,35$ & $\begin{array}{c}0.73 \\
(0.0364) \\
\end{array}$ & $(0.66,0.80)$ & $\begin{array}{c}0.71 \\
(0.1015) \\
\end{array}$ & $(0.51,0.91)$ \\
\hline & & p24 & $\begin{array}{c}100,100,93 \\
100\end{array}$ & $\begin{array}{c}100,100 \\
93,94\end{array}$ & $\mathrm{NA}^{7}$ & $N A^{7}$ & $\begin{array}{l}1.00 \\
(0.0000)\end{array}$ & $(1.00,1.00)$ \\
\hline & & ZM96 gp140 & $\begin{array}{c}100,100,100 \\
88 \\
\end{array}$ & $22,36,60,47$ & $\begin{array}{c}0.68 \\
(0.0295) \\
\end{array}$ & $(0.62,0.74)$ & $\begin{array}{c}0.77 \\
(0.0875) \\
\end{array}$ & $(0.60,0.94)$ \\
\hline & \multirow{2}{*}{$\begin{array}{l}\text { IgG3 } \\
\text { binding } \\
\text { antibody }\end{array}$} & gp41 & $67,67,94,65$ & $6,20,38,0$ & $\begin{array}{c}0.78 \\
(0.0631)\end{array}$ & $(0.65,0.90)$ & $\begin{array}{c}0.90 \\
(0.0644)\end{array}$ & $(0.78,1.00)$ \\
\hline & & p24 & $\begin{array}{c}94, \\
87,100,100 \\
\end{array}$ & $\begin{array}{c}11,20,100,7 \\
6 \\
\end{array}$ & $\begin{array}{c}0.92 \\
(0.0156) \\
\end{array}$ & $(0.89,0.95)$ & $\begin{array}{c}0.94 \\
(0.0411) \\
\end{array}$ & $(0.86,1.00)$ \\
\hline & \multirow{3}{*}{$\begin{array}{l}\text { Neutralizin } \\
\text { g antibody }\end{array}$} & MN.3 & $\begin{array}{c}100,100,100 \\
100\end{array}$ & $63,43,86,64$ & $\begin{array}{c}0.84 \\
(0.0338) \\
\end{array}$ & $(0.77,0.91)$ & $\begin{array}{c}0.93 \\
(0.0512) \\
\end{array}$ & $(0.83,1.00)$ \\
\hline & & MW965.26 & $\begin{array}{c}100,100,94,1 \\
00\end{array}$ & $19,21,14,50$ & $\begin{array}{c}0.52 \\
(0.0634)\end{array}$ & $(0.40,0.64)$ & $\begin{array}{c}0.68 \\
(0.1401)\end{array}$ & $(0.40,0.95)$ \\
\hline & & TH023.6 & $\begin{array}{c}100,93,81,10 \\
0 \\
\end{array}$ & $25,50,7,57$ & $\begin{array}{c}0.75 \\
(0.0354) \\
\end{array}$ & $(0.68,0.82)$ & $\begin{array}{c}0.86 \\
(0.0743) \\
\end{array}$ & $(0.72,1.00)$ \\
\hline & \multirow{2}{*}{ ICS } & CD4+ ENV & $44,33,94,56$ & $36,21,64,50$ & $\begin{array}{c}0.81 \\
(0.0484)\end{array}$ & $(0.72,0.91)$ & $\begin{array}{c}0.80 \\
(0.0838)\end{array}$ & $(0.63,0.96)$ \\
\hline & & $\mathrm{CD} 4+\mathrm{GAG}$ & $11,0,88,63$ & $0,0,86,57$ & $\begin{array}{c}0.98 \\
(0.0088)\end{array}$ & $(0.97,1.00)$ & $\begin{array}{c}0.93 \\
(0.0379)\end{array}$ & $(0.86,1.00)$ \\
\hline \multirow{8}{*}{$\begin{array}{c}\text { HVTN2 } \\
05^{5,6}\end{array}$} & \multirow{4}{*}{$\begin{array}{l}\text { IgG binding } \\
\text { antibody }\end{array}$} & Con 6 gp120/B & 39,78 & 6,34 & $\begin{array}{c}0.91 \\
(0.0331)\end{array}$ & $(0.85,0.98)$ & $\begin{array}{c}0.93 \\
(0.0539)\end{array}$ & $(0.83,1.00)$ \\
\hline & & Con S gp140 CFI & 93,100 & 79,100 & $\begin{array}{c}0.95 \\
(0.1033)\end{array}$ & $(0.74,1.00)$ & $\begin{array}{c}0.95 \\
(0.1231)\end{array}$ & $(0.71,1.00)$ \\
\hline & & gp41 & 89,97 & 74,83 & $\begin{array}{c}0.83 \\
(0.0604) \\
\end{array}$ & $(0.71,0.95)$ & $\begin{array}{c}0.83 \\
(0.1240) \\
\end{array}$ & $(0.58,1.00)$ \\
\hline & & p24 & 96,100 & 82,93 & $\begin{array}{c}0.86 \\
(0.1066)\end{array}$ & $(0.65,1.00)$ & $\begin{array}{c}0.81 \\
(0.1756)\end{array}$ & $(0.46,1.00)$ \\
\hline & \multirow{4}{*}{ ICS } & CD4+ ENV & 41,16 & 26,6 & $\begin{array}{c}0.89 \\
(0.0557) \\
\end{array}$ & $(0.78,1.00)$ & $\begin{array}{c}0.86 \\
(0.0922) \\
\end{array}$ & $(0.68,1.00)$ \\
\hline & & $\mathrm{CD} 4+\mathrm{GAG}$ & 77,63 & 57,48 & $\begin{array}{c}0.68 \\
(0.0507)\end{array}$ & $(0.58,0.78)$ & $\begin{array}{c}0.73 \\
(0.0806)\end{array}$ & $(0.58,0.89)$ \\
\hline & & CD8+ ENV & 23,12 & 18,9 & $\begin{array}{c}0.97 \\
(0.0290)\end{array}$ & $(0.91,1.00)$ & $\begin{array}{c}0.98 \\
(0.0185)\end{array}$ & $(0.94,1.00)$ \\
\hline & & $\mathrm{CD} 8+\mathrm{GAG}$ & 45,18 & 36,15 & 0.87 & $(0.78,0.97)$ & 0.90 & $(0.79,1.00)$ \\
\hline
\end{tabular}




\begin{tabular}{|c|c|c|c|c|c|c|c|c|}
\hline & & & & & $(0.0485)$ & & $(0.0566)$ & \\
\hline \multirow{21}{*}{ RV144 } & \multirow[t]{5}{*}{ Avidity IgG } & A244gp120gD+CHO GSID & 100 & 29 & $\begin{array}{c}0.63 \\
(0.0688)\end{array}$ & $(0.49,0.76)$ & $\begin{array}{c}0.70 \\
(0.1400)\end{array}$ & $(0.42,0.97)$ \\
\hline & & $\begin{array}{l}\text { A244gp120gDnegdelta11 } \\
293 T\end{array}$ & 100 & 21 & $\begin{array}{c}0.66 \\
(0.0947) \\
\end{array}$ & $(0.47,0.84)$ & $\begin{array}{c}0.72 \\
(0.1841) \\
\end{array}$ & $(0.36,1.00)$ \\
\hline & & MNgp120 gD+CHO GSID & 100 & 66 & $\begin{array}{c}0.67 \\
(0.0500)\end{array}$ & $(0.58,0.77)$ & $\begin{array}{c}0.83 \\
(0.1388)\end{array}$ & $(0.56,1.00)$ \\
\hline & & MNgp120 gDneg $293 T$ & 100 & 24 & $\begin{array}{c}0.62 \\
(0.0819)\end{array}$ & $(0.45,0.78)$ & $\begin{array}{c}0.63 \\
(0.1757)\end{array}$ & $(0.29,0.98)$ \\
\hline & & $\begin{array}{l}\text { MNgp120 gDneg Delta } 11 \\
\text { 293F }\end{array}$ & 100 & 71 & $\begin{array}{c}0.72 \\
(0.0610)\end{array}$ & $(0.60,0.84)$ & $\begin{array}{c}0.80 \\
(0.1382)\end{array}$ & $(0.53,1.00)$ \\
\hline & \multirow{8}{*}{$\begin{array}{l}\text { IgA binding } \\
\text { antibody }\end{array}$} & Con6gp120B & 76 & 19 & $\begin{array}{c}0.66 \\
(0.0814)\end{array}$ & $(0.50,0.82)$ & $\begin{array}{c}0.85 \\
(0.1248)\end{array}$ & $(0.61,1.00)$ \\
\hline & & Con6140CF & 78 & 16 & $\begin{array}{c}0.87 \\
(0.0835) \\
\end{array}$ & $(0.70,1.00)$ & $\begin{array}{c}0.91 \\
(0.0994) \\
\end{array}$ & $(0.71,1.00)$ \\
\hline & & $\begin{array}{l}\text { 92TH023gp120gDpos293 } \\
\text { TBerman }\end{array}$ & 92 & 54 & $\begin{array}{c}0.82 \\
(0.0347)\end{array}$ & $(0.76,0.89)$ & $\begin{array}{c}0.89 \\
(0.0860)\end{array}$ & $(0.72,1.00)$ \\
\hline & & $\begin{array}{l}\text { A244gp120gDnegdelta11 } \\
\text { 293Tmon }\end{array}$ & 78 & 22 & $\begin{array}{c}0.82 \\
(0.0690)\end{array}$ & $(0.69,0.96)$ & $\begin{array}{c}0.88 \\
(0.1158)\end{array}$ & $(0.65,1.00)$ \\
\hline & & $\begin{array}{l}\text { A244gp120gDpos293Tmo } \\
\mathrm{n}\end{array}$ & 100 & 81 & $\begin{array}{c}0.82 \\
(0.0880)\end{array}$ & $(0.65,0.99)$ & $\begin{array}{c}0.89 \\
(0.1359)\end{array}$ & $(0.62,1.00)$ \\
\hline & & GNE8rgp120Qpool & 100 & 62 & $\begin{array}{c}0.87 \\
(0.0333)\end{array}$ & $(0.80,0.93)$ & $\begin{array}{c}0.85 \\
(0.1075)\end{array}$ & $(0.63,1.00)$ \\
\hline & & $\begin{array}{l}\text { rgp120A244gDposCHOGS } \\
\text { ID }\end{array}$ & 81 & 38 & $\begin{array}{c}0.90 \\
(0.0294) \\
\end{array}$ & $(0.85,0.96)$ & $\begin{array}{c}0.90 \\
(0.0870) \\
\end{array}$ & $(0.73,1.00)$ \\
\hline & & $\begin{array}{l}\text { rgp120MNgDposCHOGSI } \\
\text { D }\end{array}$ & 92 & 57 & $\begin{array}{c}0.94 \\
(0.0219)\end{array}$ & $(0.90,0.98)$ & $\begin{array}{c}0.93 \\
(0.0620)\end{array}$ & $(0.81,1.00)$ \\
\hline & \multirow[t]{3}{*}{$\begin{array}{l}\text { IgG binding } \\
\text { antibody }\end{array}$} & $\begin{array}{l}\text { A244gp120delta11293Fm } \\
\text { onomer }\end{array}$ & 100 & 79 & $\begin{array}{c}0.74 \\
(0.0841) \\
\end{array}$ & $(0.58,0.91)$ & $\begin{array}{c}0.90 \\
(0.1065) \\
\end{array}$ & $(0.69,1.00)$ \\
\hline & & C1086C V1 V2Tags & 97 & 50 & $\begin{array}{c}0.84 \\
(0.0342) \\
\end{array}$ & $(0.77,0.90)$ & $\begin{array}{c}0.85 \\
(0.0967) \\
\end{array}$ & $(0.66,1.00)$ \\
\hline & & gp70 BCaseA2V1V2mut3 & 97 & 76 & $\begin{array}{c}0.70 \\
(0.0793) \\
\end{array}$ & $(0.54,0.85)$ & $\begin{array}{c}0.71 \\
(0.1908) \\
\end{array}$ & $(0.33,1.00)$ \\
\hline & $\begin{array}{l}\text { IgG3 } \\
\text { binding } \\
\text { antibody }\end{array}$ & gp70_BCaseA2V1V2mut3 & 95 & 24 & $\begin{array}{c}0.79 \\
(0.0635)\end{array}$ & $(0.66,0.91)$ & $\begin{array}{c}0.86 \\
(0.0978)\end{array}$ & $(0.66,1.00)$ \\
\hline & \multirow{4}{*}{$\begin{array}{l}\text { IgG4 } \\
\text { binding } \\
\text { antibody }\end{array}$} & $\begin{array}{l}\text { A244gp120gDnegdelta11 } \\
\text { 293Tmon }\end{array}$ & 11 & 21 & $\begin{array}{c}0.61 \\
(0.1034) \\
\end{array}$ & $(0.41,0.81)$ & $N A^{8}$ & $N A^{8}$ \\
\hline & & $\begin{array}{l}\text { A244gp120gDpos293Tmo } \\
n\end{array}$ & 68 & 47 & $\begin{array}{c}0.42 \\
(0.0934)\end{array}$ & $(0.24,0.61)$ & $\begin{array}{l}0.60 \\
(0.1473)\end{array}$ & $(0.31,0.89)$ \\
\hline & & GNE8rgp120Qpool & 8 & 34 & $\begin{array}{c}0.56 \\
(0.0595) \\
\end{array}$ & $(0.44,0.68)$ & $N A^{8}$ & $N A^{8}$ \\
\hline & & $\begin{array}{l}\text { rgp120MNgDposCHOGSI } \\
\text { D }\end{array}$ & 11 & 16 & $\begin{array}{c}0.47 \\
(0.1160)\end{array}$ & $(0.24,0.70)$ & $N A^{8}$ & $N A^{8}$ \\
\hline
\end{tabular}

Superscripts refer to specific vaccine regimens, as follows: ${ }^{1} \mathrm{~N} / \mathrm{N} / \mathrm{NA} / \mathrm{NA},{ }^{2} \mathrm{NA} / \mathrm{NA} / \mathrm{NA} / \mathrm{NA},{ }^{3} \mathrm{D} / \mathrm{D} / \mathrm{NA} / \mathrm{NA},{ }^{4} \mathrm{DA} / \mathrm{DA} / \mathrm{NA} / \mathrm{NA}$, ${ }^{5}$ DDMM, ${ }^{6}$ MMM. N, NYVAC (Viral Vector - Pox); NA, NYVAC/AIDSVAX (Viral Vector - Pox/Protein); D, DNA (DNA-based); DA, DNA/AIDSVAX (DNA/Protein); DDMM, DNA/DNA/modified vaccinia virus Ankara (MVA)/MVA; MMM, MVA/MVA/MVA. More details on the vaccine regimens can be found in Table 1.

${ }^{7}$ RRF models were not fitted due to close to $100 \%$ positive rates in wk52 responses.

${ }^{8}$ The number of wk26 positive responders was not sufficient to fit the model due to low wk26 responses rates.

AUC, area-under-the-curve of true positive rate vs. false positive rate at various thresholds of the predicted probability; $\mathrm{Cl}$, confidence interval; $\mathrm{CV}$, cross-validation prediction; NA, not available; OOB, out-of-bag prediction; ROC, receiver operating characteristic.

*The assay reagent name refers to the specific antigen used in the assay and typically includes information related to the particular HIV-1 protein and the relevant HIV-1 strain and/or clade. 
Table 3: Prediction of wk52 response magnitude. Regularized random forests ("same+other") were used to model wk52 response magnitude for each biomarker within each study. Univariate linear regression models were also used to predict wk52 response magnitude for each biomarker using its wk26 magnitude as the predictor. Results are reported as correlation coefficients between predicted and observed wk52 response magnitudes.

\begin{tabular}{|c|c|c|c|c|c|}
\hline Study & Assay & Assay reagent* & $\begin{array}{c}\text { Correlation coefficient } \\
\rho_{\text {obs }}(p \text {-value) between } \\
\text { observed wk26 and } \\
\text { wk52 responses }\end{array}$ & $\begin{array}{l}\text { Correlation coefficient } \rho_{\text {pred- }} \\
\text { ( } p \text {-value) between RRF- } \\
\text { predicted and observed } \\
\text { wk52 responses }\end{array}$ & $\begin{array}{l}\text { Correlation coefficient } \rho_{\text {pred- }} \\
\text { (eg-value) between } \\
\text { univariable regression- } \\
\text { predicted and observed } \\
\text { wk52 responses }\end{array}$ \\
\hline \multirow{18}{*}{$\begin{array}{l}\text { HVTN } \\
096^{1-4}\end{array}$} & $\begin{array}{l}\text { IgA binding } \\
\text { antibody }\end{array}$ & p24 & $0.62(<0.001)$ & $0.52(<0.001)$ & $0.50(<0.001)$ \\
\hline & \multirow{10}{*}{$\begin{array}{l}\text { IgG binding } \\
\text { antibody }\end{array}$} & Con 6 gp120/B & $0.60(<0.001)$ & $0.48(<0.001)$ & $0.56(<0.001)$ \\
\hline & & Con S gp140 CFI & $0.57(<0.001)$ & $0.59(<0.001)$ & $0.50(<0.001)$ \\
\hline & & $\begin{array}{l}\text { A244 gp } 120 \\
\text { gDneg/293F/mon }\end{array}$ & $0.51(<0.001)$ & $0.48(<0.001)$ & $0.44(<0.001)$ \\
\hline & & $\begin{array}{l}\text { AE.A244 V1V2 } \\
\text { Tags/293F }\end{array}$ & $0.60(<0.001)$ & $0.49(<0.001)$ & $0.44(<0.001)$ \\
\hline & & gp41 & $0.66(<0.001)$ & $0.61(<0.001)$ & $0.60(<0.001)$ \\
\hline & & $\begin{array}{l}\text { gp70 B.CaseA2 } \\
\text { V1/V2/169K }\end{array}$ & $0.46(<0.001)$ & $0.42(0.001)$ & $0.39(0.001)$ \\
\hline & & gp70 B.CaseA V1 V2 & $0.35(0.004)$ & 0.05 (ns) & $0.25(0.044)$ \\
\hline & & MN gp120 gDneg/293T & $0.37(0.003)$ & $0.36(0.004)$ & $0.27(0.034)$ \\
\hline & & P24 & $0.61(<0.001)$ & $0.55(<0.001)$ & $0.59(<0.001)$ \\
\hline & & ZM96 gp140 & $0.48(<0.001)$ & $0.43(<0.001)$ & $0.46(<0.001)$ \\
\hline & \multirow{2}{*}{$\begin{array}{l}\text { IgG3 binding } \\
\text { antibody }\end{array}$} & gp41 & $0.51(<0.001)$ & $0.34(0.007)$ & $0.49(<0.001)$ \\
\hline & & $\mathrm{p} 24$ & $0.82(<0.001)$ & $0.82(<0.001)$ & $0.80(<0.001)$ \\
\hline & \multirow{3}{*}{$\begin{array}{l}\text { Neutralizing } \\
\text { antibody }\end{array}$} & MN.3 & $0.73(<0.001)$ & $0.64(<0.001)$ & $0.71(<0.001)$ \\
\hline & & MW965.26 & $0.31(0.017)$ & 0.01 (ns) & $0.27(0.039)$ \\
\hline & & TH023.6 & $0.60(<0.001)$ & $0.36(0.008)$ & $0.56(<0.001)$ \\
\hline & \multirow{2}{*}{ ICS } & CD4+ENV & $0.63(<0.001)$ & $0.6(<0.001)$ & $0.61(<0.001)$ \\
\hline & & CD4+ GAG & $0.82(<0.001)$ & $0.75(<0.001)$ & $0.81(<0.001)$ \\
\hline \multirow{8}{*}{$\begin{array}{l}\text { HVTN } \\
205^{5,6}\end{array}$} & \multirow{4}{*}{$\begin{array}{l}\text { IgG binding } \\
\text { antibody }\end{array}$} & Con 6 gp120/B & $0.65(<0.001)$ & $0.63(<0.001)$ & $0.58(<0.001)$ \\
\hline & & Con S gp140 CFI & $0.58(<0.001)$ & $0.39(0.004)$ & $0.57(<0.001)$ \\
\hline & & gp41 & $0.59(<0.001)$ & $0.43(0.001)$ & $0.53(<0.001)$ \\
\hline & & p24 & $0.35(0.005)$ & $0.46(0.001)$ & $0.26(0.037)$ \\
\hline & \multirow{4}{*}{ ICS } & CD4+ENV & $0.57(<0.001)$ & $0.58(<0.001)$ & $0.55(<0.001)$ \\
\hline & & CD4+ GAG & $0.59(<0.001)$ & $0.58(<0.001)$ & $0.56(<0.001)$ \\
\hline & & CD8+ ENV & $0.89(<0.001)$ & $0.86(<0.001)$ & $0.88(<0.001)$ \\
\hline & & CD8+ GAG & $0.77(<0.001)$ & $0.72(<0.001)$ & $0.76(<0.001)$ \\
\hline \multirow{14}{*}{ RV144 } & \multirow[t]{5}{*}{ Avidity IgG } & $\begin{array}{l}\text { A244gp120gD+CHO } \\
\text { GSID }\end{array}$ & $0.36(0.027)$ & 0.23 (ns) & 0.27 (ns) \\
\hline & & $\begin{array}{l}\text { A244gp120gDnegdelta1 } \\
1293 T\end{array}$ & $0.35(0.033)$ & 0.04 (ns) & 0.16 (ns) \\
\hline & & MNgp120 gD+CHO GSID & $0.62(<0.001)$ & $0.53(0.001)$ & $0.58(<0.001)$ \\
\hline & & MNgp120 gDneg 293T & 0.27 (ns) & 0.11 (ns) & 0.09 (ns) \\
\hline & & $\begin{array}{l}\text { MNgp120 gDneg Delta } \\
11293 \mathrm{~F}\end{array}$ & $0.56(<0.001)$ & $0.33(0.04)$ & $0.53(0.001)$ \\
\hline & & Con6gp120B & $0.51(0.001)$ & $0.36(0.03)$ & $0.46(0.004)$ \\
\hline & & Con6140CF & $0.54(0.001)$ & $0.52(0.001)$ & $0.50(0.002)$ \\
\hline & IgA binding & $\begin{array}{l}\text { 92TH023gp120gDpos29 } \\
\text { 3TBerman }\end{array}$ & $0.80(<0.001)$ & $0.7(<0.001)$ & $0.78(<0.001)$ \\
\hline & antibody & $\begin{array}{l}\text { A244gp120gDnegdelta1 } \\
\text { 1293Tmon }\end{array}$ & $0.58(<0.001)$ & $0.55(<0.001)$ & $0.57(<0.001)$ \\
\hline & & $\begin{array}{l}\text { A244gp120gDpos293Tm } \\
\text { on }\end{array}$ & $0.92(<0.001)$ & $0.86(<0.001)$ & $0.91(<0.001)$ \\
\hline & & GNE8rgp120Qpool & $0.73(<0.001)$ & $0.72(<0.001)$ & $0.68(<0.001)$ \\
\hline & & $\begin{array}{l}\text { rgp120A244gDposCHOG } \\
\text { SID }\end{array}$ & $0.73(<0.001)$ & $0.68(<0.001)$ & $0.71(<0.001)$ \\
\hline & & $\begin{array}{l}\text { rgp120MNgDposCHOGSI } \\
\text { D }\end{array}$ & $0.89(<0.001)$ & $0.82(<0.001)$ & $0.88(<0.001)$ \\
\hline & IgG binding & A244gp120delta11293F & $0.69(<0.001)$ & $0.57(<0.001)$ & $0.67(<0.001)$ \\
\hline
\end{tabular}




\begin{tabular}{|c|c|c|c|c|}
\hline \multirow[t]{3}{*}{ antibody } & monomer & & & \\
\hline & C1086C V1 V2Tags & $0.64(<0.001)$ & $0.48(0.003)$ & $0.54(<0.001)$ \\
\hline & gp70 BCaseA2V1V2mut3 & $0.38(0.018)$ & $0.55(<0.001)$ & $0.22(\mathrm{~ns})$ \\
\hline $\begin{array}{l}\text { IgG3 binding } \\
\text { antibody }\end{array}$ & $\begin{array}{l}\text { gp70_BCaseA2V1V2mut } \\
3\end{array}$ & $0.51(0.001)$ & 0.26 (ns) & $0.43(0.007)$ \\
\hline \multirow[t]{4}{*}{$\begin{array}{l}\text { IgG4 binding } \\
\text { antibody }\end{array}$} & $\begin{array}{l}\text { A244gp120gDnegdelta1 } \\
\text { 1293Tmon }\end{array}$ & 0.24 (ns) & 0.24 (ns) & 0.29 (ns) \\
\hline & $\begin{array}{l}\text { A244gp120gDpos293Tm } \\
\text { on }\end{array}$ & 0.18 (ns) & $-0.11(n s)$ & 0.05 (ns) \\
\hline & GNE8rgp120Qpool & 0.19 (ns) & 0.2 (ns) & 0.17 (ns) \\
\hline & $\begin{array}{l}\text { rgp120MNgDposCHOGSI } \\
\text { D }\end{array}$ & 0.06 (ns) & 0.1 (ns) & -0.21 (ns) \\
\hline
\end{tabular}

331 Superscripts refer to specific vaccine regimens, as follows: ${ }^{1} \mathrm{~N} / \mathrm{N} / \mathrm{NA} / \mathrm{NA},{ }^{2} \mathrm{NA} / \mathrm{NA} / \mathrm{NA} / \mathrm{NA},{ }^{3} \mathrm{D} / \mathrm{D} / \mathrm{NA} / \mathrm{NA},{ }^{4} \mathrm{DA} / \mathrm{DA} / \mathrm{NA} / \mathrm{NA}$, ${ }^{5}$ DDMM, ${ }^{6}$ MMM. N, NYVAC (Viral Vector - Pox); NA, NYVAC/AIDSVAX (Viral Vector - Pox/Protein); D, DNA (DNA-based); DA, DNA/AIDSVAX (DNA/Protein); DDMM, DNA/DNA/modified vaccinia virus Ankara (MVA)/MVA; MMM, MVA/MVA/MVA. More details on the vaccine regimens can be found in Table 1.

ns, non-significant $p$-value (>0.05).

*The assay reagent name refers to the specific antigen used in the assay and typically includes information related to the particular HIV-1 protein and the relevant HIV-1 strain and/or clade. 
FIGURE LEGENDS

Figure 1: Individual immune response trajectories from wk26 to wk52 across the 7 vaccine regimens in HVTN096, HVTN205 and RV144. Net IgG BAMA responses to three different HIV antigens (gp120, gp41, and V1V2) (Panel A) and CD4+ ICS immune responses to two different HIV antigens (Env, Gag) (Panel B) were assessed using serum samples (Panel A) or peripheral blood mononuclear cells (Panel B) from vaccine recipients in HVTN096, HVTN205, and RV144 with $n=15-18 /$ group, 32-46/group, and 38-40, respectively. Note that RV144 BAMA assays used a 1:40 dilution and responses were baseline-subtracted, whereas HVTN096 and HVTN204 BAMA assays used a 1:50 dilution and responses were not baseline-subtracted. Red and blue dots indicate positive and negative responses, respectively. Responses for biomarkers with a wk52 response rate $<15 \%$ are not shown. BAMA, binding antibody multiplex assay; ICS, intracellular cytokine staining. Superscripts refer to specific vaccine regimens, as follows: ${ }^{1} \mathrm{~N} / \mathrm{N} / \mathrm{NA} / \mathrm{NA},{ }^{2} \mathrm{NA} / \mathrm{NA} / \mathrm{NA} / \mathrm{NA},{ }^{3} \mathrm{D} / \mathrm{D} / \mathrm{NA} / \mathrm{NA}$, ${ }^{4}$ DA/DA/NA/NA, ${ }^{5}$ DDMM, ${ }^{6}$ MMM. N, NYVAC (Viral Vector - Pox); NA, NYVAC/AIDSVAX (Viral Vector - Pox/Protein); D, DNA (DNA-based); DA, DNA/AIDSVAX (DNA/Protein); DDMM, DNA/DNA/modified vaccinia virus Ankara (MVA)/MVA; MMM, MVA/MVA/MVA. More details on the vaccine regimens can be found in Table 1.

Figure 2: Spearman correlation coefficients between observed wk26 vs. wk52 responses of the same biomarker or of the observed wk26 response of one biomarker vs. the observed wk52 response of another biomarker, as measured by Cellular and Antibody assays. Spearman correlation coefficients were determined for observed immune responses of the same biomarker at wk26 vs wk52 (Panel A) or for the observed wk26 response of one biomarker vs. the observed wk52 response of another biomarker (Panel B) as measured by Cellular (ELISpot, ICS, and Luminex) and Antibody (binding antibody, avidity, and neutralizing antibody) assays. Correlation coefficients were determined for responses in vaccine recipients in HVTN096, HVTN205 and RV144 who received all planned vaccinations and who were HIVuninfected at the time of immune response measurement. ELISpot, enzyme-linked immunospot; ICS, intracellular cytokine staining.

Figure 3: Scatter plots of RRF-predicted vs. observed antibody responses in RV144 comparing the ability of the two RRF models to predict wk52 responses. Serum IgA antibody responses of RV144 vaccine recipients to gp120 (Panels A and B; ${ }^{1}$ A244gp120gDpos293Tmon and ${ }^{2}$ GNE8rgp120Qpool) and serum IgG antibody responses to V1V2 (Panel C;

\footnotetext{
${ }^{3} \mathrm{BC}$ aseA2V1V2mut3) antigens were determined at wk26 and wk52. RRF models were used to predict the wk52
} 
responses using either the wk26 response of the same biomarker (left panels, "Same WK26 Response") or using the wk26 response of the same biomarker in addition to the wk26 responses of all other measured biomarkers (right panels, "Same + Other WK26 Responses"). $\rho$ indicates the spearman correlation coefficient between the observed and predicted wk52 response magnitudes. P-value indicates the significance of $\rho$ being different from zero. Fitted simple linear regression lines are included in each panel. Ig, immunoglobulin; RRF, regularized random forest. 
A

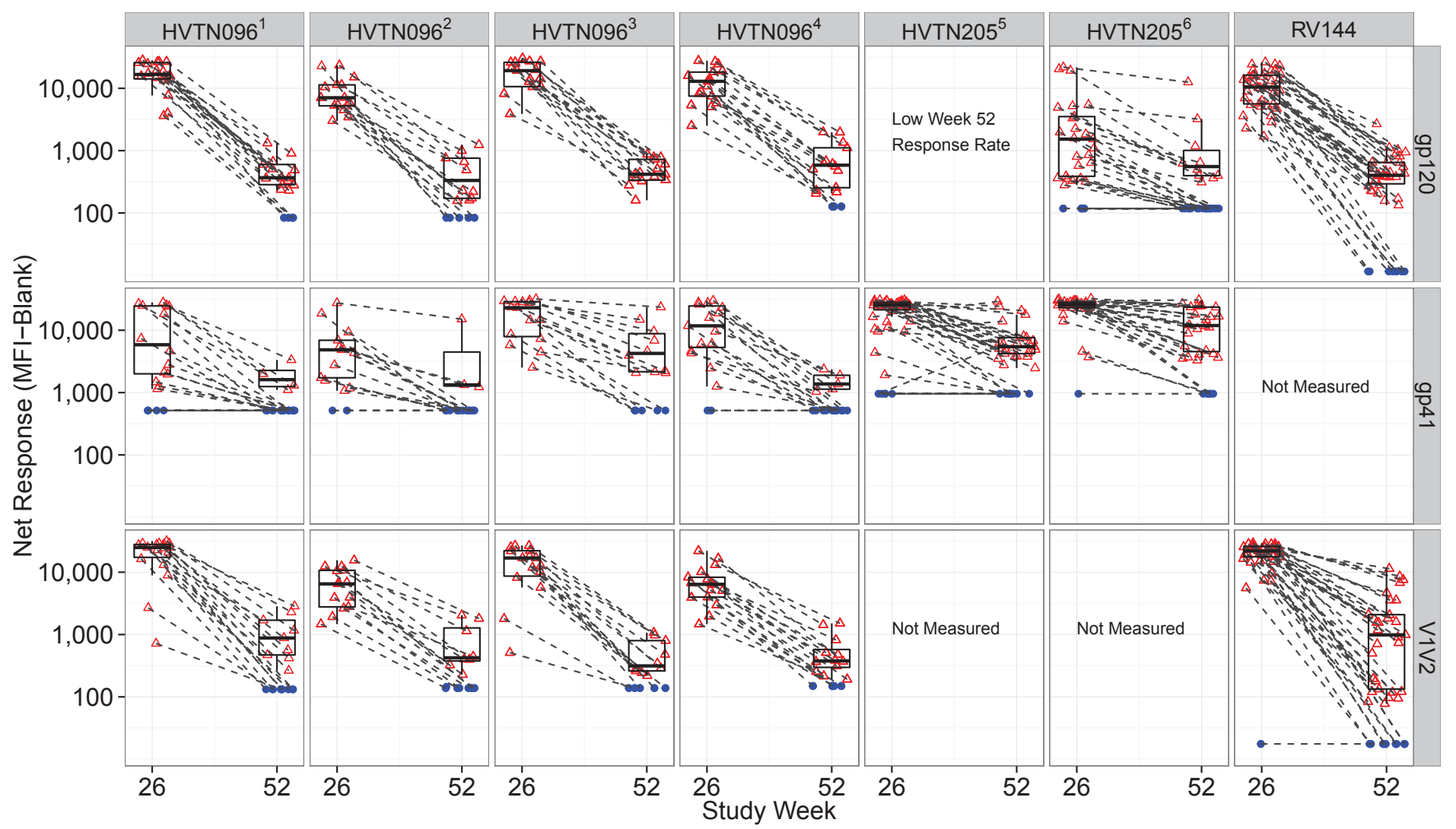

B

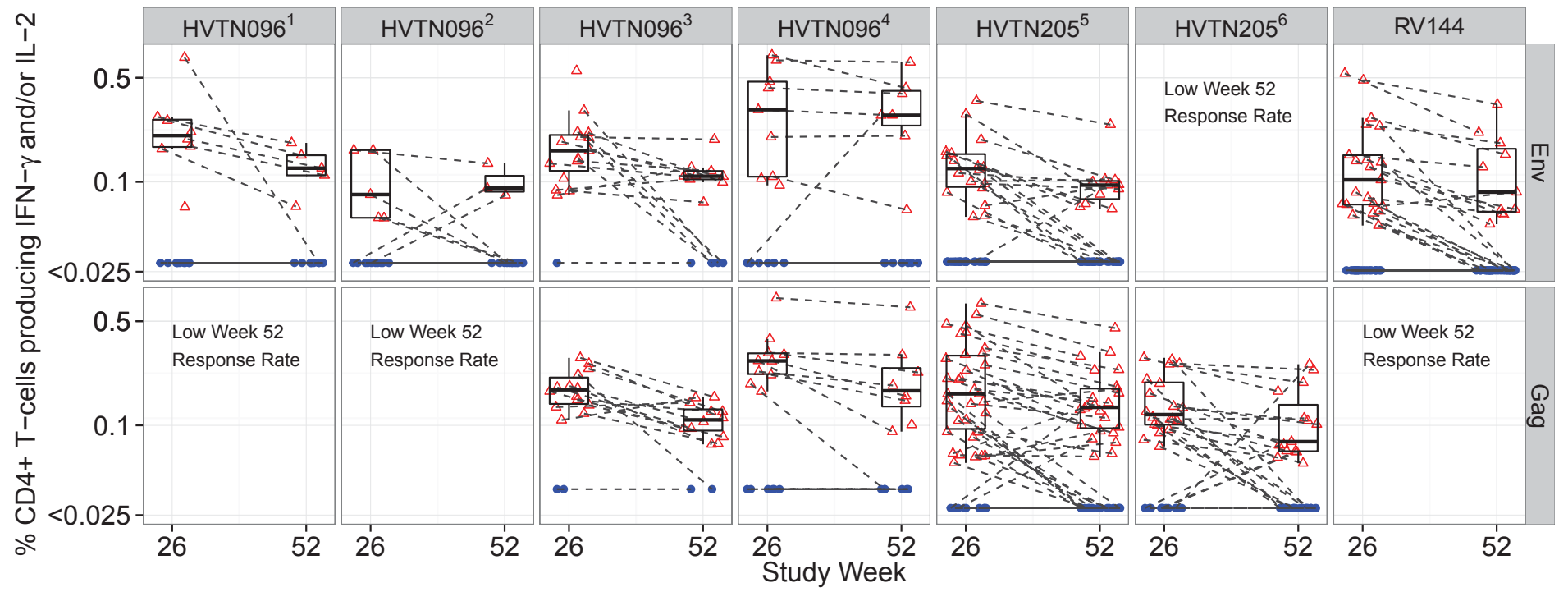

a Positive a Negative 


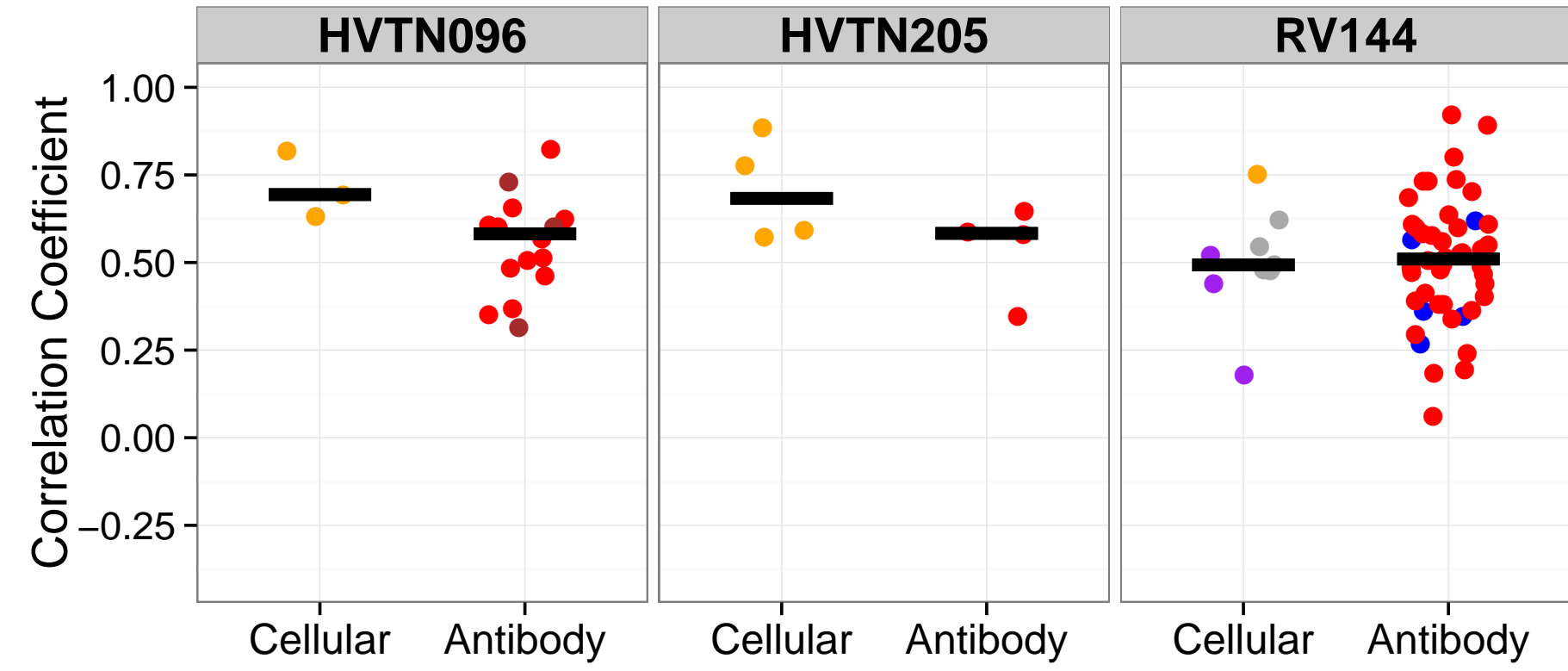

- Bcell ELISPOT $\bullet$ ICS $\bullet$ Luminex $\bullet$ Binding Antibody $\bullet$ Avidity $\bullet$ NAB

B
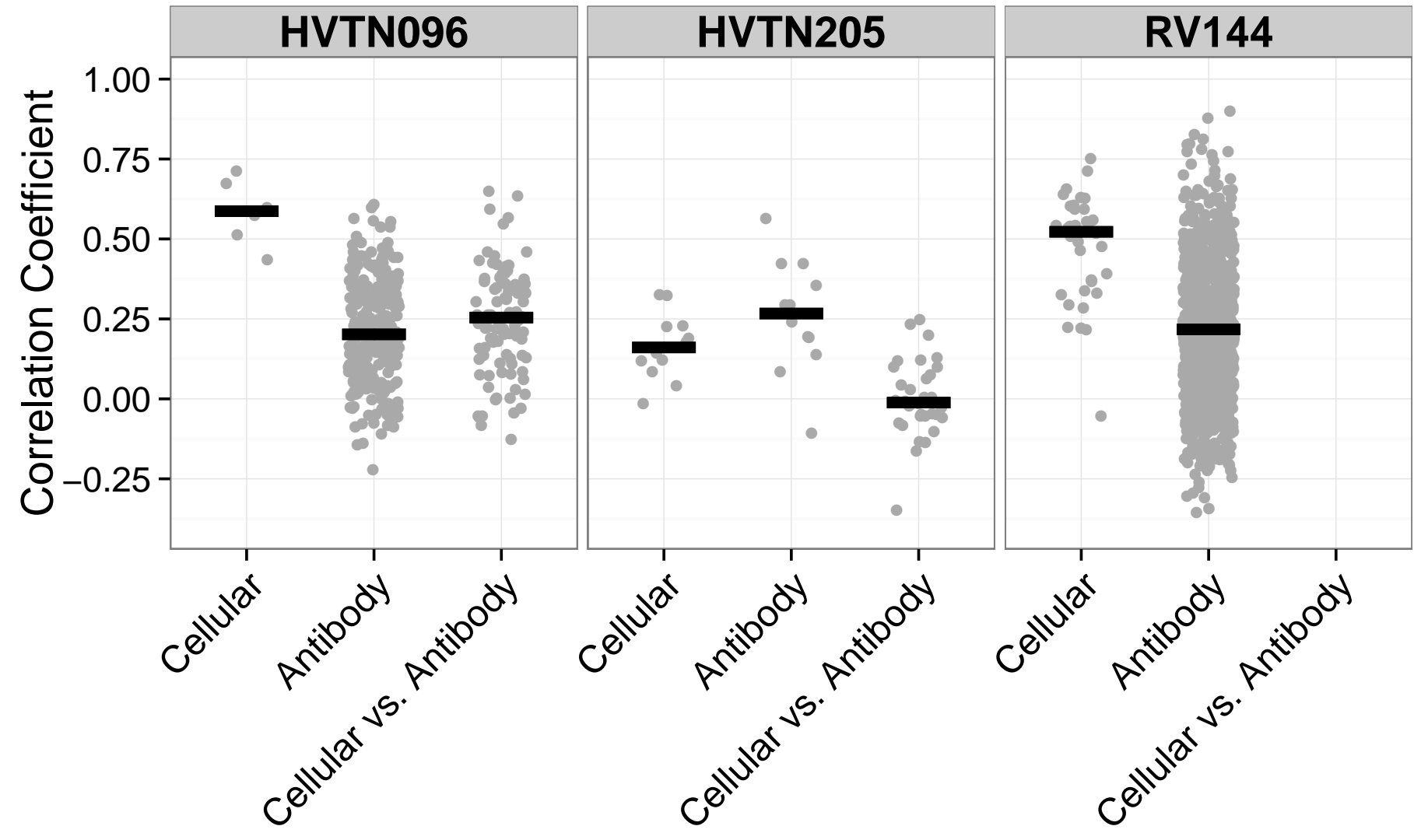
